\title{
The Immunological Reactivity of Organism Under the Opiomania
}

\author{
Kulmukanova $\mathrm{K} \mathrm{K}^{1}$, Baiduissenova $\mathrm{A} \mathrm{U}^{2 *}$, Akhmediyarova $\mathrm{E} \mathrm{A}^{3}$, Yktiyarov $\mathrm{A} \mathrm{A}^{2}$, Bekniyazova \\ $\mathrm{G} \mathrm{A}^{2}$ and Rakhmetova $\mathrm{N} \mathrm{B}^{2}$ \\ ${ }^{1}$ Chair of Psychiatry and Narcology, NJSC Astana Medical university, Kazakhstan \\ ${ }^{2}$ Chair of Microbiology and virology named after Sh I Sarbasova, NJSC Astana Medical University, Kazakhstan
}

${ }^{3}$ Chair of Allergology and Immunology, NJSC Astana Medical university, Kazakhstan

*Corresponding author: Baiduissenova A U, Chair of Microbiology and virology named after Sh I Sarbasova, NJSC Astana Medical University, Nur-Sultan, Kazakhstan.

To Cite This Article: Kulmukanova K K, Baiduissenova A U, Akhmediyarova E A, Yktiyarov A A, Bekniyazova G A, Rakhmetova N B. The Immunological Reactivity of Organism Under the Opiomania. Am J Biomed Sci \& Res. 2021 - 12(6). AJBSR.MS.ID.001805.

DOI: 10.34297/AJBSR.2021.12.001805.

Received: 眥 April 30, 2021; Published: 㘹 May 11, 2021

Keywords: Immunological reactivity, Opiomania, psychiatry and narcology, Reactivity of organism, Opiate dependence

\section{Introduction}

In connection with the general trend of changes in reactivity in many exogenous and endogenous diseases, nowadays more attention is paid to changes in immunological reactivity in drug addiction. The feasibility of assessing the state of immune mechanisms is determined by the need to predict their course and outcome [1,2].

A few researchers have found that patients with opium addiction have functional insufficiency of polymorphonuclear leukocytes and T-lymphocytes, a decrease in the percentage of T- and B-lymphocytes, macrophages in the blood; decreased natural killer cell activity and antibody-dependent cell-mediated cytotoxicity; autoimmune disorders are noted [2-4].

In other studies, on the contrary, an increase in the absolute number of T-lymphocytes of peripheral blood in drug addicts was found, and it was also revealed that both during the period of abstinence and during the period of remission there is a significant increase in IgM and T-lymphocytes [2]. In addition, recently there has been a growing interest in the detection of anti-morphine antibodies in the blood in opium addiction. A significant increase in the level of anti-morphine antibodies was not typical for other types of drug addiction [5]. A direct dependence of the degree of absorption of complement by blood serums in the presence of morphine on the severity of drug tolerance in patients with opium addiction was recorded [6].

The aim of the study was to study the immunological reactivity in patients with opiate dependence in a state of abstinence.

\section{Materials and Methods}

Clinical and immunological studies were carried out in 80 patients (64 men and 16 women) who use homemade opium group preparations. All 80 patients were injected with drugs intravenously. Clinically diagnosed with stage 2 of the disease with a detailed clinical picture of the disease, represented by a large drug addiction syndrome. The patients were hospitalized in a narcological hospital. The age of the patients was from 15 to 40 years, the duration of the disease ranged from 0.5 to 19 years. Of these, the duration of the disease up to 3 years - in 28 patients (group 1), and over 3 years - in 52 patients (group 2). An assessment of the mental, narcological, somatic, and neurological status was carried out. General clinical, biochemical, and immunological parameters were studied.

Immunological studies were carried out in dynamics: upon admission to the hospital, after 7 days and after 14 days against the background of ongoing withdrawal syndrome therapy. In the blood, 
T- and B-lymphocytes, subpopulations of T cells, immunoglobulins of classes A, G, M were determined by a unified method. The control group consisted of 50 apparently healthy individuals matched by age and sex.

\section{Results}

The results of the study of indicators of cellular and humoral immunity in patients with opium addiction are presented in Table 1. Upon admission to the clinic, a decrease in T-lymphocytes by $24.4 \%$ was found compared to the control group ( $\mathrm{p}<0.05$ ). Analysis of $\mathrm{T}$ cell subpopulations in the examined patients revealed a $26.7 \%$ decrease in I-zelpers and by $37.5 \%$ in T-suppressors ( $p<0.05)$. At the same time, there was an increase in the number of null cells by $25 \%(\mathrm{p}<0.05)$ (Table 1).

Table 1: Indicators of cellular and humoral immunity in patients with opium addiction in a state of abstinence (M $\pm m)$.

\begin{tabular}{|c|c|c|c|c|}
\hline \multirow{2}{*}{ Indicators } & \multirow{2}{*}{ Control group, $\mathbf{n = 5 0}$} & \multicolumn{3}{|c|}{ Experimental group, $\mathbf{n}=\mathbf{8 0}$} \\
\cline { 3 - 5 } & & $\begin{array}{c}\text { Upon admission to the } \\
\text { hospital }\end{array}$ & $7^{\text {th }}$ day & $\mathbf{1 4}^{\text {th }}$ day \\
\hline T-lymphocytes (\%) & $53,1 \pm 1,5$ & $40,17 \pm 2,86^{*}$ & $42,0 \pm 4,9^{*}$ & $34,5 \pm 6,1^{*}$ \\
\hline B-lymphocytes (\%) & $10,2 \pm 0,9$ & $12,3 \pm 1,29$ & $10,3 \pm 1,3$ & $8,8 \pm 1,8$ \\
\hline O-cells (\%) & $36,6 \pm 1,97$ & $45,8 \pm 2,7^{*}$ & $30,9 \pm 4,4$ & $31,5 \pm 5,7$ \\
\hline T-helpers (\%) & $42,3 \pm 1,31$ & $31,0 \pm 2,18^{*}$ & $23,3 \pm 4,4^{* *}$ & $30,6 \pm 3,9^{*}$ \\
\hline T-suppressors (\%) & $18,7 \pm 0,62$ & $13,6 \pm 1,35^{*}$ & $11,3 \pm 1,54^{* *}$ & $10,25 \pm 2,1^{* *}$ \\
\hline Tx/Tc & $2,7 \pm 0,17$ & $2,9 \pm 0,3$ & $2,5 \pm 0,4$ & $1,9 \pm 0,4^{*}$ \\
\hline Ig A (g/l) & $1,76 \pm 0,18$ & $1,71 \pm 0,16$ & $1,79 \pm 0,16$ & $0,8 \pm 0,2^{*}$ \\
\hline Ig M (g/l) & $0,9 \pm 0,07$ & $2,3 \pm 0,2^{* *}$ & $1,9 \pm 0,3^{*}$ & $1,01 \pm 0,5^{*}$ \\
\hline Ig G (g/l) & $8,38 \pm 0,58$ & $9,6 \pm 1,2$ & $8,7 \pm 1,4$ & $10,7 \pm 2,2$ \\
\hline
\end{tabular}

Note: * - reliability of differences in relation to the control group $-p<0.05^{*},-p<0.001^{* \star}$

From the side of humoral immunity indices, the Ig M shifts were more informative, the value of which was 2.5 times higher than in the control group $(\mathrm{p}<0.05)$, which is consistent with the literature data.

According to several authors, an increase in the level of Ig M in the blood serum in opium addicts was more common than in other types of drug addiction, which, apparently, can serve as a hallmark of opium addiction [7]. Serum Ig levels of classes A and G did not show any visible deviations from normal values.

Despite the ongoing therapy of withdrawal symptoms on days 7 and 14, the body's immunological reactivity did not recover, the patients persisted in T-lymphocytopenia, and a decrease in the level of immunoregulatory $\mathrm{T}$ cells was observed (Table 2).

We analyzed the indicators of cellular and humoral immunity in opium addiction in a state of abstinence, depending on the duration of the disease.

As can be seen from Table 2, patients of group 1 had more pronounced T-lymphocytopenia. A persistent increase in the value of serum Ig M was revealed both in the dynamics of abstinence and depending on the duration of the disease, which may indicate the tension of the humoral link of immunity in opium addiction. In addition, as the duration of chronic anesthesia increases, there is a tendency to an increase in the relative number of B-lymphocytes.

Table 2: Indicators of cellular and humoral immunity in opium addiction in a state of abstinence, depending on the duration of the disease (M $\pm m)$.

\begin{tabular}{|c|c|c|c|}
\hline Indicators & Control group, $n=50$ & $1^{\text {st }}$ group (up to 3 years), $n=28$ & $2^{\text {nd }}$ group (over 3 years), $n=52$ \\
\hline T-lymphocytes (\%) & $53,1 \pm 1,5$ & $37,5 \pm 4,1^{*}$ & $46,2 \pm 2,7^{*}$ \\
\hline B-lymphocytes (\%) & $10,2 \pm 0,9$ & $10,8 \pm 0,9$ & $13,1 \pm 1,8$ \\
\hline O-cells (\%) & $36,6 \pm 1,97$ & $52,5 \pm 4,4^{*}$ & $42,6 \pm 3,2$ \\
\hline T-helpers (\%) & $42,3 \pm 1,31$ & $28,4 \pm 3,9^{*}$ & $31,8 \pm 2,5^{*}$ \\
\hline T-suppressors (\%) & $18,7 \pm 0,62$ & $10,23 \pm 1,9 * *$ & $15,7 \pm 1,6$ \\
\hline $\operatorname{Ig} A(g / l)$ & $1,76 \pm 0,18$ & $1,3 \pm 0,3$ & $1,7 \pm 0,2$ \\
\hline $\operatorname{Ig} M(g / l)$ & $0,9 \pm 0,07$ & $1,9 \pm 0,3 *$ & $2,4 \pm 0,3^{* *}$ \\
\hline $\operatorname{Ig} \mathrm{G}(\mathrm{g} / \mathrm{l})$ & $8,38 \pm 0,58$ & $8,12 \pm 1,5$ & $10,57 \pm 1,5$ \\
\hline
\end{tabular}

Note: * - reliability of differences in relation to the control group $-p<0.05^{*},-p<0.001^{* *}$ 


\section{Discussion}

Considering the data on the presence of anti-brain antibodies in the blood in opium addiction, it can be assumed that, namely, antibrain antibodies determine an increase in the content of serum Ig M. As is known, Ig M, having a high pathogenic potential, reacting with polymorphonuclear leukocytes, promotes development in the focus with chronic antigenic stimulation of immunocomplex inflammation and can aggravate destructive processes. The changes we obtained on the part of immunological parameters are consistent with the data of experimental studies, which showed that long-term administration of morphine to animals stimulates the formation of specific antibodies in them, which neutralize the pharmacological effects of the drug. This may indicate the importance of the formation of antibodies in the development of dependence on opiates and indicates the important role of immunological changes in the body in the development of drug addiction [8]. The latter is confirmed by works showing that the appearance of high levels of antigen-specific cells and antibodies that bind neurotransmitters has a significant effect on the course of opium addiction. Summing up, we can say that patients with opium addiction in a state of abstinence develop T-lymphocytopenia; with an increase in the duration of the disease, an increase of 2-2.6 times in the level of Ig M is observed; the revealed changes in the organism's immunological reactivity suggest the need to include immunoreactive therapy in the complex of therapeutic measures for opium addiction.

\section{Acknowledgment}

We express our sincere gratitude and appreciation to the head of the Department of Microbiology and Virology named after
Sh.I. Sarbasova of Astana Medical University, Doctor of Medical Sciences, Professor Dusmagambetov Marat Uteuovich for providing the opportunity to work at the Department of Microbiological Laboratory.

\section{References}

1. Tsygan VN, Akperov EK, Vostrikov VV, Shabanov PD (2007) Immune dysfunctions in drug addicts and methods of their correction. Reviews on Clinical Pharmacology and Drug Therapy 5(4): 2-81.

2. Cossarizza A, Chang HD, Andreas Radbruch, Andreas Acs, Dieter Adam (2019) Guidelines for the use of flow cytometry and cell sorting in immunological studies (second edition). Eur J Immunol 49(10): 14571973.

3. Kovalev IA, Sharkova VA (2016) Clinical and immunological features of opium addiction. Modern Problems of Science and Education pp. 6.

4. Shatyrko MA, Reshetnikov IV, Golodny SV, Mingazov AKh, Kozochkin DA, et al. (2015) Features of changes in the immunogram and indicators of free radical oxidation of blood plasma in HIV-infected heroin addicts. Kazan Medical Journal 96(5): 772-775.

5. Chechet EA, Isaikin AI, Chernenko OA, Yakhno NN, Savushkina IYu (2014) Chronic inflammatory demyelinating polyradiculopathy and moderate cognitive impairment in a patient suffering from heroin addiction, infected with HIV and the hepatitis C virus. Neurological journal 19(2): 38-46.

6. Khasina MA, Molochnikov VO, Makhachkeeva TA, Khasina My (2015) Bioelements in the correction of dysmetabolic disorders in drug addicts. Pacific Medical Journal 1: 48-50.

7. Litvintsev BS (2015) Damage to the nervous system in drug addiction: features of symptoms and neurological complications. Bulletin of the Russian Military Medical Academy 1(49): 95-100.

8. Nevidimova TI, Vetlugina TP, Batukhtina EI, Savochkina DN, Naydenova NN, et al. (2015) Features of cytokine production in addiction diseases. International Journal of Applied and Basic Research 1(1): 49-51. 